\title{
El combate de los trillizos y la imagen de la guerra civil en las Púnicas de Silio Itálico*
}

\author{
Jesús Bartolomé \\ UPV/EHU \\ jesus.bartolome@ehu.eus \\ ORCID iD: http://orcid.org/0000-0002-5274-404X
The fight of the triplet brothers and the image of the civil war in the Punica of Silius Italicus

\begin{abstract}
El objetivo de este artículo es estudiar el episodio del combate de los trillizos que Silio Itálico inserta en el relato de la batalla del Tesino (Sil. IV 355400). Partiendo del intertexto liviano (Liv. I 25) se analizan las variaciones que el poeta flavio introduce con respecto a su modelo. La narración de Silio acentúa algunas características propias de la guerra civil, pero culmina con el elogio de los combatientes en una clara alusión al apóstrofe dirigido a Euríalo y Niso (Aen. IX 446-449). Esta táctica, aparentemente contradictoria pero totalmente deliberada, contribuye a definir el concepto de épica con respecto a sus predecesores Virgilio y Lucano y sus contemporáneos, especialmente Estacio. Los textos similares que se analizan del autor de la $T e-$ baida así parecen demostrarlo.
\end{abstract}

Palabras clave: Silio Itálico; Estacio; Épica; Intertextualidad; Guerra civil.
The goal of this paper is to study the episode of the fight between two sets of triplet brothers that Silius Italicus inserts in the account of the battle of Ticinus (Sil. IV 355-400). Taking Livy's intertext (Liv. I 25) as a starting point, the changes the Flavian epicist introduces with respect to his model are analized. Silius emphasizes some of the characteristics of civil war already apparent in Livy's narrative; however, the episode is closed by the praise to the fighters in a clear allusion to the famous apostrophe to Euryalus and Nisus (Aen. IX 446-449). This strategy, apparently contradictory but totally deliberate, contributes to define the concept of epic in relation to his predecessors Virgil and Lucan, and his contemporaries, especially Statius. The texts of the Thebaid with which these of the Punica are compared seem to prove it.

Key words: Silius Italicus; Statius; Epic; Intertextuality; Civil War.

Cómo citar este artículo / Citation: Bartolomé, Jesús 2018: «El combate de los trillizos y la imagen de la guerra civil en las Púnicas de Silio Itálico», Emerita 86 (1), pp. 109-132.

* Este trabajo se inserta en el ámbito del Grupo de investigación Oedipodioniae Thebae. Biblioteca digital grecorromana sobre la guerra civil (Thebas), Ref. FFI2015-68599-R (MINECO/FEDER), y del grupo de investigación de la UPV/EHU GIU 16/64.

Copyright: (C) 2018 CSIC. Este es un artículo de acceso abierto distribuido bajo los términos de la licencia de uso y distribución Creative Commons Reconocimiento 4.0 Internacional (CC BY 4.0). 


\section{La evocación de la guerra civil en las Púnicas}

Es un hecho conocido que las referencias y alusiones a las guerras civiles romanas son un tema esencial de la obra de los poetas épicos flavios ${ }^{1}$, y que el modo de su presentación se encuentra estrechamente vinculada con la forma de concebir el género épico. Estacio elige un tema mítico, el de la saga tebana, convertida en arquetipo de las luchas civiles: fraternas acies (Theb. I 1). Silio adopta una actitud distinta pues su proyecto de cantar el pasado más glorioso de Roma como tema para su épica histórica, descarta una cuestión tan conflictiva como las guerras civiles. El proemio de su obra define un programa alejado de Estacio y especialmente de Lucano, como lo muestran los términos que compendian el objetivo de su poema: gloria (I 1) y decus (I 3) ${ }^{2}$, opuestos al que condensa el contenido de la Farsalia: nefas. Sin embargo, a lo largo del poema se encuentran claros indicios que permiten matizar esta opinión y entender que Silio refleja la imposibilidad de restaurar la epopeya romana histórica celebrativa prescindiendo del cuestionamiento que de ella realiza Lucano³.

${ }^{1}$ Marks 2005, pp. 274-276 y n. 104, recoge las diferentes propuestas realizadas sobre la cuestión. Por su parte, Dominik 2017, de acuerdo con el Abstract publicado por el autor de un trabajo de próxima aparición, resume la importancia de la presencia de las guerras civiles en los épicos flavios: "One of the topics that characterizes Roman writers, especially the Neronian and Flavian epicists, and puts them very much in contact with their own society is that of civil war». Las estrategias para integrar dicho tema en las obras respectivas difieren, sin embargo. Estacio, como señala McNelis 2007, p. 4, recurre como tema al mito de Tebas, que se encontraba muy cargado de connotaciones y significado. Roma y Tebas compartían similitudes importantes que hacían a la ciudad griega particularmente atractiva a los escritores romanos para confrontar las actitudes y valores de su sociedad. Valerio Flaco, aunque retorne a un mito sin relación con el tema de la guerra civil, lo incorpora en sus Argonáuticas, como demuestran McGuire 1997, pp. 103-113, Fucecchi 2006, y Río Torres-Murciano 2006.

2 Algunos estudiosos definen a Silio como un anti-Lucano: Albrecht 1964, p. 24, Küppers 1986, pp. 50-51, Laudizi 1989, p. 67; Ripoll 1998, pp. 524-28, considera que, pese a las contradicciones, la concepción unitaria y coherente de la ética heroica da a la obra su cohesión interna y su orientación general positiva. Marks, por su parte sin llegar a esos extremos, defiende la idea de que Itálico, lejos de censurar la Roma imperial, quiere proyectar una imagen de Roma ideal (2005, pp. 265-276), aunque reconoce igualmente que comparte con Lucano el disgusto por las guerras civiles. Ahl, Davis, Pomeroy 1986, p. 2519, y Fucecchi 1999, p. 338, exponen una idea similar pero hacen especial hincapié en el pesimismo de la obra de Silio sobre la realidad contemporánea.

${ }^{3}$ Véase Bartolomé 2009a y 2009b. Landrey 2014, passim, destaca la lectura problemática que Silio hace de la Eneida y evidencia los aspectos de guerra civil que esconde el contenido de las Púnicas. 
Esta dualidad se observa con más facilidad si tenemos en cuenta el carácter elástico del tiempo en la obra de Itálico (Dominik 2003, p. 471). Esto permite una fusión cronológica de distintas etapas de la historia de Roma, y favorece las lecturas alusivas de los acontecimientos narrados, de modo que el lector pueda con facilidad leer en paralelo episodios míticos e históricos de épocas diferentes.

La crítica ha reconocido una serie de recursos directos e indirectos de los que se sirve Silio Itálico para la evocación de las guerras civiles del final de la república y de las que él mismo vivió. Las formas de evocación pueden ser muy sutiles y con ello polémicas, matizadas muy a menudo por la intertextualidad con Virgilio (Ganiban 2007) y, sobre todo, con Lucano ${ }^{4}$. Entre los recursos utilizados se encuentran el uso de los nombres propios de protagonistas destacados de la guerra civil (McGuire 1997, pp. 136-144), el diseño de una serie de episodios de tal manera que evocan, de forma directa o indirecta, las guerras civiles dentro del relato de la Segunda Guerra Púnica. Estos episodios están moldeados de acuerdo con características propias de guerra civil en los que destaca la densa relación intertextual con Lucano: el suicidio colectivo de los saguntinos 5 , la construcción de la batalla de Cannas, el eje central de las Púnicas, en clave de guerra civil siguiendo el modelo de Farsalia. Este planteamiento ya se encontraba en Livio (XXII 41.6 y 44.5), quien entendía la discordia entre los generales y también la discordia dentro de la sociedad romana como elemento explicativo de la derrota de Cannas y de la mayoría de derrotas romanas ${ }^{6}$. Asimismo, McGuire 1997, p. 32, indica un tercer recurso para introducir el tema de la guerra civil en su obra: las repetidas alusiones a escenas de guerra civil de la Tebaida. Por último, en el episodio del descenso a los infiernos de Escipión, el anuncio del futuro resulta absolutamente devastador; en cuanto que lejos del modelo de Virgilio, que anuncia la historia gloriosa de Roma y su culminación con Augusto, los únicos personajes del futuro de Roma que se presentan son los responsables de la guerra civil, precisamente aquéllos señalados por Lucano en el libro I de su Farsalia: Mario, Sila, Pompeyo y César (Sil. XIII 853-867) ${ }^{7}$.

${ }^{4}$ Ahl, Davis, Pomeroy 1986, p. 2519, Marks 2010.

${ }_{5}$ McGuire 1997, pp. 207-219, Ripoll 1998, pp. 407-410, Dominik 2003, pp. 485-496, Tipping 2010a, p. 35, Marks 2010, p.132, y 2013.

${ }^{6}$ Ahl, Davis, Pomeroy 1986, Fucecchi 1999, Ariemma 2000 y 2008, McGuire 1997, pp. 126146, Marks 2005, p. 284, y 2010, pp. 136-139, Bartolomé 2009a y 2009b, Tipping 2010a y 2010 b.

${ }^{7}$ Ahl, Davis, Pomeroy 1986, pp. 2523-2531, Fucecchi 1999, Tipping 2010a, p. 35 ss. Sobre la cuestión en general, Marks 2010, p. 128, y Tipping 2010b, pp. 217-218. 
En esa misma línea se encuentran las referencias al mito de fundación o a Rómulo mismo o su forma divinizada, Quirino. La figura de Rómulo presenta unas características ambiguas por su condición de fundador de Roma, pero también de responsable, directo o indirecto, según las versiones, de la muerte de su hermano Remo. El fratricidio se convierte en un antecedente simbólico de las guerras civiles 8 , como se observa en los escritores augusteos y en especial Horacio (epod. VII 17-20), y más tarde en Lucano y los épicos flavios9. De ahí que los combates entre gemelos, como el que estudiaremos, siempre sean susceptibles de evocar el mito del fundador de Roma y, en consecuencia, de la guerra civil ${ }^{10}$.

\section{La lucha de los trillizos}

Tomando estos hechos como punto de partida, y centrándonos en la obra de Silio Itálico, estudiaremos la escena del combate entre dos grupos de trillizos que se inserta en el relato de la batalla del Tesino (Sil. IV 355-400). El estudio de este pasaje y su comparación con otros textos similares, tanto de las Púnicas como de la Tebaida de su contemporáneo Estacio, nos permitirá determinar con argumentos sólidos el procedimiento seguido por Silio para incardinar los elementos propios de la glorificación de Roma con las advertencias y temores sobre la guerra civil vividas por él de forma tan cercana, así como observar la profunda reflexión sobre la propia obra poética y sobre la concepción polémica del género épico que plantea el autor y que se desprende del denso tejido de relaciones intratextuales e intertextuales presentes en su obra.

El inicio del libro IV de las Púnicas supone el comienzo de una sucesión de derrotas romanas que culminarán con la de Cannas en el libro X. Dichas derrotas son, en palabras de Marks 2010, p. 128, derrotas autodestructivas de Roma, y en ellas la idea de la guerra civil se encuentra muy presente ${ }^{11}$.

${ }^{8}$ Ariemma 2008, p. 343. Por su parte, Micozzi 1999, p. 359, n. 37, señala como precedentes de la conversión del mito de la fundación en antecedente de la guerra civil a Cicerón, de off. III 41 y Catulo LXIV 397 ss.

9 Remitimos a Bartolomé 2010 para el tratamiento del mito de Rómulo en la Farsalia; a Tipping 2010a, pp. 23-26, para el estudio del mito del fundador de Roma en Silio; para el de la Tebaida a Dominik 1994, p. 153.

${ }^{10}$ Sobre el uso del mito como símbolo del enfrentamiento especular, con el doble, Hardie 1993a, p. 57.

${ }^{11}$ Los libros IV-X exponen las derrotas autodestructivas de Roma, como señala Marks 2010, pp. 132-143. El Libro IV, como inicio de este proceso, cumple una función especial. La evocación de las guerras civiles se hace a menudo a través de la intertextualidad con Lucano. 
Si nos detenemos en el intertexto de Livio, y nos centramos en el contexto en el que se integra el pasaje del historiador romano (I 23), observamos un hecho digno de atención. Livio, así como la tradición historiográfica romana, incluyen el enfrentamiento entre los dos grupos de trillizos en el marco de la guerra entre Roma y Alba Longa durante el reinado de Tulo Hostilio ${ }^{12}$. Este combate se acuerda como solución menos cruel que la lucha general entre los dos ejércitos de ambas ciudades (sine magna clade, sine multo sanguine utriusque populi decerni possit... Liv. I 23.10). La lucha se plantea en términos muy próximos a los de la guerra civil, y esto no solo en el relato del famoso combate, sino también en todo el episodio de la guerra contra Alba Longa, ciudad predecesora de la de Roma, en el que se inserta el episodio. Los términos con los que define la lucha el historiador paduano son muy claros:

et bellum utrimque summa ope parabatur, ciuili simillimum bello, prope inter parentes natosque, Troianam utramque prolem, cum Lauinium ab Troia, ab Lauinio Alba, ab Albanorum stirpe regum oriundi Romani essent (Liv. I 23.2)

Más tarde el jefe de Alba, Metio Fufecio, se refiere a la relación entre Alba y Roma calificándola como: duos cognatos uicinosque populos (I 23.7). Al parentesco entre los dos pueblos se suma la relación familiar entre los dos grupos de trillizos. Tito Livio no habla de parentesco de Horacios y Curiacios; sin embargo, Dionisio de Halicarnaso (Ant. Rom. III 13.4; III 15.2) hace a los trillizos primos hermanos. Livio no reconoce dicho parentesco -aunque señala que no se sabe quiénes eran los romanos y quiénes los albanos-, pero sí establece lazos entre ambas familias en el final del combate, cuando el vencedor da muerte a su hermana, prometida a uno de los Curiacios (I 28.2). Es decir, el historiador incide en la cercanía de este conflicto con una guerra civil ${ }^{13}$.

El encaje del episodio en el nuevo contexto no es sencillo y por ello Silio se esfuerza en este empeño. La elección de los trillizos espartanos, hijos de Jantipo, protagonista de la victoria sobre Régulo, conecta el episodio con la primera guerra púnica y, por ello, con el resto de la obra. De este modo, se

12 Se trata de uno de esos mitos patrióticos con los que Roma se cuenta a sí misma, como indica Mencacci 1987, p. 131.

${ }^{13}$ La insistencia en la identidad y semejanza de los combatientes subraya la misma idea, como señala Mencacci 1987, p. 132 ss., que entiende el combate como una renovación del enfrentamiento de Rómulo y Remo. 
subraya la continuidad y los lazos genealógicos entre los combatientes de las dos guerras púnicas (Ripoll 1998, pp. 278-279), cuya máxima expresión se indica desde el inicio de la obra al señalar la relación entre Aníbal y su padre (I 70-140). La idea de emulación de las hazañas paternas se destaca asimismo cuando señala la motivación para la lucha de los trillizos espartanos. Por otro lado, con este recurso el episodio no queda aislado pues la figura de Régulo adquiere un protagonismo considerable en las Púnicas por su condición de paradigma de la fides romana frente a la perfidia cartaginesa ${ }^{14}$.

Igualmente trata de acomodar el combate a la tradición de la que parte, la histórica, y la épica, más allá de la utilización de motivos narrativos de una y otra. La elección de gemelos procedentes de Alba remite directamente al texto de Livio y, así, a los orígenes míticos del relato. Los nombres de los hermanos romanos (Virbius, Capys y Albanus) recogen la tradición mítica de Livio y la Eneida no hacen sino reforzar la conexión intertextual con dichas obras $^{15}$. Por otro lado, la elección de unos trillizos de origen espartano sitúa el combate en el ámbito de la leyenda de los orígenes en cuanto que recrea en este pequeño cuadro el enfrentamiento entre griegos y troyanos (o sus descendientes), conectando así el texto plenamente en la tradición épica. Además, la procedencia de este grupo le sirve para recrear el paisaje lacedemonio, que traslada al lector a la patria de los Dióscuros, ejemplo de gemelos bien avenidos, como señala Mencacci 1994, p. 29; y ello tiene sus consecuencias para la interpretación del texto, como veremos:

Tergemini primam ante aciem fera proelia fratres 355 miscebant, quos Ledaeo Sidonia Barce

Xanthippo felix uteri inter bella crearat.

res Graiae ductorque parens ac nobile Amyclae nomen et iniectus Spartanis colla catenis

Regulus inflabant ueteri praecordia fama. 360

Marte probare genus factisque Lacona parentem

${ }^{14}$ La derrota de Régulo por Jantipo, y su posterior captura se evoca en el libro sexto. A Régulo le dedica un amplio excurso en VI 62-551; remitimos a Fröhlich 2000, y Fucecchi 2003, pp. 272-284.

15 La intertextualidad de Silio, y del resto de los poetas flavios, es extremadamente rica y compleja. Littlewood 2011, pp. xxi-xxviii, ofrece un buen resumen de las diferentes formas de las que se sirve el autor de las Púnicas. También son de interés el planteamiento y los resultados de los análisis intertextuales de Chaudhuri, Dexter, Bonilla Lopez 2015. 
ardebant gelidosque dehinc inuisere montis

Taygeta et tandem bellis innare subactis

Eurotan patrium ritusque uidere Lycurgi.

sed Spartam penetrare deus fratresque negarunt

Ausonii, totidem numero, quos miserat altis

Egeriae genitos immitis Aricia lucis,

aetatis mentisque pares; at non dabat ultra

Clotho dura lacus aramque uidere Dianae.

namque ut in aduersos impacti turbine pugnae

Eumachus et Critias et laetus nomine patris

Xanthippus iunxere gradus, ceu bella leones

inter se furibunda mouent et murmure anhelo

squalentis campos ac longa mapalia complent-

omnis in occultas rupis atque auia pernix

Maurus saxa fugit, coniunxque Libyssa profuso

uagitum cohibens suspendit ab ubere natos;

illi dira fremunt, perfractaque in ore cruento

ossa sonant, pugnantque feri sub dentibus artus-

haud secus Egeriae pubes, hinc Virbius acer,

hinc Capys, adsiliunt paribusque Albanus in armis.

subsidens paulum perfossa proruit aluo

Albanum Critias; ast illi cuncta repente

implerunt clipeum miserando uiscera lapsu.

Eumachus inde Capyn; sed tota mole tenebat

ceu fixum membris tegimen; tamen improbus ensis

adnexam parmae decidit uulnere laeuam,

inque suo pressa est non reddens tegmina nisu

infelix manus atque haesit labentibus armis.

ultima restabat fusis iam palma duobus

Virbius. huic trepidos simulanti ducere gressus

Xanthippus gladio, rigida cadit Eumachus hasta,

et tandem aequatae geminato funere pugnae.

inde alterna uiris transegit pectora mucro,

inque uicem erepta posuerunt proelia uita.

felices leti, pietas quos addidit umbris!

optabunt similes uenientia saecula fratres, aeternumque decus memori celebrabitur aeuo, si modo ferre diem serosque uidere nepotes carmina nostra ualent, nec famam inuidit Apollo.

(Sil., IV 355-400). 
El ajuste de esta escena -muy célebre y, por ello, muy caracterizada-, a una batalla como la del Tesino exige algunas alteraciones importantes, aunque no todas las que practica Silio son estrictamente necesarias. Una de las realizadas ha sido la de despojar el relato de toda presencia de espectadores y de las características de espectáculo anfiteatra ${ }^{16}$. Esta acción le permite centrarse en los aspectos concretos del combate y su ejecución. Entre ellos destacan el afán de gloria (vv. 358-362) como motivación para la lucha y la estilización de la acción heroica a través del símil de los leones (vv. 372-379), un medio recurrente para la transformación del relato histórico en épico y una forma de anclaje en la tradición del género ${ }^{17}$. Se reserva, en cambio, el autor para sí mismo el comentario de la acción con una intervención en primera persona en el apóstrofe final, en claro contraste con otro de los textos que comentaremos ${ }^{18}$.

Pese a la importancia de esta modificación del texto de Livio que introduce Silio, creemos que se dan al menos otras tres de mayor calado.

En primer lugar, el texto original, caracterizado ya con rasgos propios de guerra civil, procedentes de su modelo principal, Livio, se inserta en el contexto de la guerra contra los cartagineses, esto es, contra el enemigo externo por antonomasia para los romanos, encarnados aquí en dos tríos, uno romano y otro griego, dejando fuera, en apariencia, evocaciones sombrías. Es decir, reelabora el marco del enfrentamiento originario entre trillizos, el de la guerra civil. La posibilidad de que el lector captara las connotaciones de guerra civil que poseía el texto original serían, sin embargo, muy considerables.

A ello contribuye igualmente la elaboración forma ${ }^{19}$, pues, gracias a los juegos de simetrías y quiasmos con los que se construye este relato y la insistencia en el uso de los términos que indican la semejanza (aetatis mentes

16 Sólo conserva alguna alusión al mundo del espectáculo, como el uso de palma, v. 390.

17 Von Albrecht 1964, pp. 90-117. El símil remite en última instancia a Homero Il. XVI 756, como apunta Spaltenstein 1986, ad IV 563.

${ }_{18}$ Ariemma 2008, pp. 330-339, examina el carácter de espectáculo gladiatorio en escenas similares en las que se mediatizan las emociones del lector a través de los espectadores internos. Que Silio prescinda de este instrumento tan extendido en la obra de Lucano y la de los poetas flavios, puede responder al deseo de eliminar toda posible connotación negativa que pueda tener la presentación como un juego gladiatorio, en contraste con el combate de los hermanos hispanos, que se desarrolla en el trascurso de unos juegos; o bien, al deseo de limitar la valoración de los acontecimientos narrados de forma exclusiva por parte del poeta en persona que dirige el apóstrofe final a los muertos. En ambos casos el propósito sería el mismo: magnificar el combate.

${ }^{19}$ De acuerdo con el análisis de Niemann 1975, pp. 69-70. 
pares, paribus in armis, iunxere gradus, fratres $)^{20}$, enfatiza la idea de la similitud a lo largo del combate y da prueba de la unidad entre el tema y los recursos formales que emplea.

En segundo lugar, la operación de transformación es aún más intensa en la reelaboración del desenlace del combate. La lucha concluye con la muerte doble (iuncta mors) de la última pareja de gemelos, de modo que no queda superviviente alguno y tampoco un vencedor. Esta modificación lo aleja totalmente del desenlace del combate de los Horacios y Curiacios (Sil. IV 391395 y Liv. I 25.8-13) y lo aproxima al resultado de otro tipo de combates, especialmente al de aquellos que se producen entre hermanos o personajes con una estrecha vinculación, aquellos que simbolizan la guerra civil ${ }^{21}$. Mediante la transformación del desenlace del episodio con respecto a sus fuentes lo que consigue Silio es acomodarlo a un modelo de muerte contrario, en apariencia, a las expectativas que los intertextos tanto históricos como épicos generan; pero, evidentemente, se trata de una aproximación pretendida $\mathrm{y}$ buscada como pone de manifiesto un tercer hecho.

En efecto, este aspecto se acentúa con la culminación del episodio pues el final del combate se clausura con un apóstrofe en el que se elogian las muertes gloriosas de los trillizos. Es una alusión manifiesta al famoso apóstrofe de Virgilio $^{22}$ a Euríalo y Niso (Aen., IX 446-449: Fortunati ambo! Si quid mea carmina possunt, / nulla dies unquam memori uos eximet aeuo, / dum domus Aeneae Capitoli immobile saxum / accolet imperiumque pater Romanus habebit), ejemplo de pietas reutilizado en el mismo sentido positivo en que lo emplea Virgilio ${ }^{23}$.

No obstante, resulta sorprendente el recurso a este intertexto virgiliano en un relato que no encuentra ninguna semejanza en su estructura narrativa. Igualmente llama la atención una vez más la introducción de un elemento

${ }^{20}$ Mencacci 1987, pp. 132-133, Hardie 1993b, p. 97, Ariemma 2008.

${ }^{21}$ El adjetivo alterna (alterna ... pectora, Sil. IV 394) es una de las marcas características de este tipo de muerte: Theb. XI 70, Theb. VIII 70, Ov. Trist. V 5, 30. En sentido positivo, lo encontramos en Theb. II 643 y V 722. Tampoco conviene olvidar que su posición en el primer verso de la Tebaida (alterna regna), lo convierte en término clave de esta.

${ }^{22}$ Niemann 1975, p. 71 y n. 1, señala las semejanzas formales y de estructura de ambos textos. Cf. igualmente Spaltenstein 1986, ad loc.

${ }^{23}$ Como indica McGuire 1997, p. 81, Virgilio reserva sus comentarios sobre el poder de su poesía para las muertes nobles a manos del enemigo. En este caso, y a diferencia de la práctica frecuente de los épicos flavios, Silio recupera el modelo virgiliano. Sobre la importancia de la pietas en Silio, remitimos a Ripoll 1998, pp. 278-279. 
perturbador en un contexto inesperado: en medio de la celebración de una acción cuyo carácter heroico se subraya por diversos medios, como hemos señalado más arriba. Efectivamente, sirviéndose de la doble perspectiva temporal que el apóstrofe contiene, incluye una alusión a las guerras civiles posteriores (v. 397) con ciertas resonancias del apóstrofe que pone fin al combate entre Eteocles y Polinices (Theb. XI 574-579: ite truces animae funestaque Tartara leto / polluite et cunctas Erebi consumite poenas! / uosque malis hominum, Stygiae, iam parcite, diuae: / omnibus in terris scelus hoc omnique sub aeuo / uiderit una dies, monstrumque infame futuris / excidat, et soli memorent haec proelia reges), en el que Estacio subvierte por completo el sentido del apóstrofe virgiliano ${ }^{24}$. Se trata de una alusión crucial a la hora de interpretar el pasaje, por la potencialidad metapoética así como por el alto grado de contraste y ambigüedad que introduce ${ }^{25}$.

La densa intertextualidad virgiliana, que subrayan tanto Ripoll 1998, p. 279, como Hardie 1993b, y también la intertextualidad con su contemporáneo, son esenciales para explicar estas aparentes contradicciones ${ }^{26}$. Asimismo, debemos tener en cuenta los aspectos intratextuales de las Púnicas como medio de interpretación. En suma, consideramos que se establece en este texto un importante diálogo metaliterario con los predecesores y con Estacio, a través del texto clave de Virgilio. El sentido de este diálogo se hace más evidente si tenemos en cuenta que los poetas flavios tienden a unir los comentarios sobre el valor conmemorativo de la poesía con los actos de suicidio, a diferencia de la práctica virgiliana que los reserva para las muertes heroicas a manos del enemigo, como afirma McGuire 1997, pp. 22-24. Silio,

${ }^{24}$ Encontramos en este caso el mismo procedimiento que destaca McGuire 1997, p. 81, como práctica de Silio y que consiste en comparar, cuando las elogia, las hazañas de los héroes de la Segunda Guerra Púnica con las menos nobles de las épocas posteriores o de su propio tiempo, como en XIV 684-688.

${ }^{25}$ Se asemeja al deseo que expresa Estacio en el epílogo del combate decisivo de la Tebaida (XI 574-579). Es un deseo que se sabe imposible de cumplir, pero puede expresarse gracias a la doble perspectiva del apóstrofe: la literaria y la histórica, como indica Bessone 2011, pp. 80-81. Las similitudes que señala Spaltenstein 1986, ad loc. con Virgilio, Georg. II 498 y 510, y Aen. VI 608 son útiles, pues, pese a que el autor citado defiende su condición de tópico, su uso en este caso tiene implicaciones más profundas.

26 Lovatt 2010, p. 160, entiende que la presentación del fratricidio en el juego gladiatorio como espectáculo es «his nod to history and the politics of contemporary spectacle». Esta es una de las razones que puede explicar su supresión en el combate de los trillizos, como hemos señalado en la nota 18 . 
en cambio, sigue en este caso la práctica virgiliana, con lo que este pasaje cobra un relieve especial ${ }^{27}$.

Así pues, el episodio, en apariencia un combate más en medio de la batalla, con un carácter singular y mayor dramatismo por la condición de los contendientes, resulta relevante por las distintas circunstancias señaladas, pero adquiere todavía una mayor trascendencia por la vinculación temática que establece con la actuación de Escipión que se desarrolla a continuación, ejemplo asimismo de pietas, virtud esencial de la Eneida. En efecto, la lucha y el epílogo del combate de los trillizos sirve de preparación y anticipación de la acción de Escipión, uno de los grandes protagonistas de la obra, que mejor ilustra esta virtud, en especial por la salvación de su padre en medio de la batalla (IV 401-479) ${ }^{28}$, una acción descrita por Silio con una imagen plenamente virgiliana (II 721-723) ${ }^{29}$.

\section{Los intertextos}

La relevancia del combate entre los trillizos se acentúa si tenemos en consideración otra serie de relaciones intratextuales e intertextuales que se obser$\operatorname{van}^{30}$. Antes de pasar al estudio de los pasajes cruciales, conviene recordar un célebre episodio de Estacio cuya relación con el texto de Silio problematiza su lectura: la lucha entre los gemelos de Argos y los gemelos de Tebas. Cuando los vencedores descubren, al intentar despojarlos de sus armas, que los vencidos son también gemelos, reconocen la muerte de sus enemigos como nefas, un término reservado regularmente para los actos de guerra civil, asesinato, etc., como si matar a otro grupo de gemelos fuera algo cercano al fratricidio (Theb. VIII 448-452) ${ }^{31}$ :

${ }^{27}$ Un ejemplo del tipo contrario en Silio lo encontramos en XIII 369-370, donde elogia el suicidio del guerrero campano Táurea.

${ }^{28}$ Así lo deja intuir Hardie 1993b, p. 97.

${ }^{29}$ Sobre los aspectos oscuros de la pietas de Escipión, cf. Ahl, Davis, Pomeroy 1986, pp. 2544-2545, Tipping 2010a, p. 154 ss.

${ }^{30}$ No vamos a entrar en la cuestión de la cronología de las Púnicas y la Tebaida, para lo que remitimos a Marks 2010, n. 3, Lovatt 2005, p. 248, 2010 y 2013, y Ripoll 2015; pero sí nos interesa recordar que se aprecian numerosas relaciones entre ambos autores flavios, en las que no siempre es fácil establecer la prioridad. El libro editado por Manuwald y Voigt 2013 es una buena prueba de ello y de lo fructífero de ese planteamiento.

${ }^{31}$ McGuire 1997, p. 124, lo compara con el enfrentamiento que está a punto de producirse entre Cástor y Pólux en Arg. III 186-189. 
Inachidae gemini geminos e sanguine Cadmi occultos galeis (saeua ignorantia belli) perculerant ferro; sed dum spolia omnia caesis eripiunt, uidere nefas, et maestus uterque respicit ad fratrem pariterque errasse queruntur.

Sin embargo, si consideramos que en el texto de Silio no hay ninguna referencia similar, la posible alusión de un pasaje al otro permite sostener la existencia de un diálogo que pretende establecer un neto contraste en el significado de ambos episodios. El carácter especular de este tipo de combates que propone Hardie 1993b, p. 97, se cancela mediante el resto de recursos que potencian una valoración positiva del acto de los trillizos. No obstante, no deja de evocarlo pues ambos episodios comparten la función de anticipar las guerras civiles posteriores y el combate final entre los hermanos, respectivamente.

En cuanto a las relaciones intratextuales, hay que destacar un pasaje, éste mucho más comentado, en el que Silio somete un suceso narrado por Livio (XXVIII 21) a un proceso de modificación similar al que acabamos de analizar. Nos referimos al combate entre dos hispanos que se enfrentan por el trono en el contexto de los juegos ofrecidos por Escipión en honor de su padre y su tío (XVI 277-591). Según la versión de Livio, los hispanos Orsua y Corbis son primos (patrueles); Silio, que no indica sus nombres, los convierte en hermanos gemelos. A ésta se añade una segunda modificación que responde exactamente a la remodelación del combate entre los trillizos ${ }^{32}$, ya que, al margen de otros detalles, la lucha finaliza con la muerte de ambos contendientes, en vez de con la victoria de uno de ellos, la de Corbis en el relato histórico de Livio $^{33}$. Este segundo cambio es completamente acorde con el anterior, pues así consigue adaptarlo al paradigma de la muerte entre hermanos ${ }^{34}$. El elemento gemelar se inserta dentro de un esquema narrativo

32 De acuerdo con Marks 2005, p. 184, y Aricò 2010, p. 130, y en contra de la opinión de Spaltenstein 1990, p. 434, que considera de poca importancia la modificación del parentesco con respecto a Livio.

33 Algunos de los cambios efectuados sobre el texto de Livio los recoge Spaltenstein 1990, ad XVI 533, aunque es más explícito Marks 2005, pp. 184-185, que señala los siguientes: el cambio de relación familiar, la muerte doble, el énfasis añadido a la crueldad y la impiedad de los hermanos, y el pathos mediante la evocación de la historia de Eteocles y Polinices. Cf. igualmente Lovatt 2010, pp. 160-161.

${ }^{34}$ Así lo indica Ripoll 2015, p. 431: «The most likely hypothesis is that Silius re-wrote the historical anecdote about the Spanish cousins he had found in Livy in such a way as to make 
preciso y sustancialmente distinto, el de los hermanos enemigos en lucha por el reino, como muestra con claridad el epílogo, que remite al de Eteocles y Polinices en la Tebaida (XII 429-36) ${ }^{35}$, sin olvidar la mediación de Lucano (I 550-552):

nec, quos culpa tulit, quos crimina noxia uitae, sed uirtus animusque ferox ad laudis amorem, hi creuere pares ferro; spectacula digna Martigena uulgo ${ }^{36}$ suetique laboris imago. hos inter gemini ${ }^{37}$ (quid iam non regibus ausum? aut quod iam regni restat scelus?) impia circo innumero fratres, cauea damnante furorem, pro sceptro armatis inierunt proelia dextris. is genti mos dirus erat, patriumque petebant orbati solium lucis discrimine fratres. concurrere animis, quantis confligere par est quos regni furor exagitat, multoque cruore exsatiata simul portantes corda sub umbras occubuere. pari nisu per pectora adactus intima descendit mucro; superaddita saeuis ultima uulneribus uerba; et, conuicia uoluens, dirus in inuitas effugit spiritus auras.

nec manes pacem passi. nam corpora iunctus una cum raperet flamma rogus, impius ignis dissiluit, cineresque simul iacuisse negarunt. (XVI 529-48)

El resultado de estas intervenciones lo convierte en un pasaje con un gran poder alusivo, acentuado por el hecho de que nos encontramos ante el único ejemplo de gemelos enfrentados que encontramos en la obra de Silio, poeta que parece sentir una verdadera predilección por las escenas de gemelos en la batalla, como afirma Mencacci 1994, p. 25.

La similitud en la estructura narrativa ahonda la distancia en el contenido entre el enfrentamiento entre los trillizos y el de los gemelos hispanos, sin

it look more like the fate of the Theban brothers. This allows us to speak of an allusive intention, bearing the value of a homage to a famous scene which is the climax of the Thebaid».

${ }_{35}$ Cf. Stat., Theb. VIII 65-74, 4.400, Ou., Trist V 5,30, y Sen., Oed. 321-327.

36 Posible alusión a los gemelos Rómulo y Remo, de acuerdo con Ariemma 2008, p. 330.

${ }^{37}$ Hos inter gemini parece un eco de IV 355: tergemini. 
llegar a anular la posibilidad de interpretarlos como dos formas diversas de expresar el mismo anhelo de superación de la guerra civil o de señalar los peligros que subyacen en la victoria.

Si en el primer caso modifica a Livio con la intención de aproximar el relato a las coordenadas de la muerte entre hermanos, en el segundo realiza la misma operación de forma aún más evidente, y a la vez matiza su significado negativo mediante un comentario sin ambigüedades. La sombra de la muerte de Eteocles y Polinices que ambos textos proyectan, el primero de ellos de forma un tanto contradictoria, el segundo de manera consecuente, es otro factor más de relación. El contexto en el que se incluye el relato no es ajeno a esta operación en cuanto que la pietas, primero la de los trillizos, después la de Escipión, posee un valor funcional importante. El segundo relato responde a principios similares poniendo como contrapunto a las disputas de los hermanos hispanos la buena relación entre Escipión y su hermano Lucio (vv. 580 ss.) $)^{38}$. Las diferencias con Livio nos invitan a leer este combate entre hermanos como oposición a la buena relación entre Escipión y su hermano, como afirma Marks 2005, p. 185.

Si consideramos ahora el resto de las relaciones intertextuales con Estacio y tenemos en cuenta el vínculo entre el episodio de los gemelos hispanos y el combate final ${ }^{39}$ entre Eteocles y Polinices (la actitud del público cauea damnante, XVI 532, la referencia a la ambición de poder como motivo de lucha, el combate mismo y el detalle de la pira funeraria cuyas llamas se separan, XVI 546-548: nam corpora iunctus / una cum raperet flamma rogus, impius ignis / dissiluit, cineresque simul iacuisse negarunt $)^{40}$, la relación paradójica que ya hemos señalado entre el final de los trillizos y el de Eteocles y Polinices se hace más visible:

nec plura locutus concidit et totis fratrem grauis obruit armis... ite truces animae funestaque Tartara leto

${ }^{38}$ Es precisamente en este contexto donde se encuentra la profecía de Marte sobre el futuro de Escipión (Sil. IV 472-77).

${ }^{39}$ Los ejemplos contrapuestos son como relatos especulares, cf. Bessone 2011, p. 83, n. 5, sobre Hopleo.

${ }^{40}$ Según McGuire 1997, p. 99 y Lovatt 2005, p. 254 ss., el episodio en su conjunto es una especie de Tebaida en miniatura; Ariemma 2008, p. 362, en cambio, considera exagerada la denominación pues reduce la Tebaida a un contexto lúdico-gladiatorio. 
polluite et cunctas Erebi consumite poenas!

uosque malis hominum, Stygiae, iam parcite, diuae:

omnibus in terris scelus hoc omnique sub aeuo

uiderit una dies, monstrumque infame futuris

excidat, et soli memorent haec proelia reges. (Theb. XI 570-579)

De este modo, la interpretación del episodio de los trillizos parece situarse en una encrucijada, ya que, por un lado, el relato evoca la contienda civil, por otro, en cambio, concluye con una exaltación de la virtud de los combatientes muertos, hecho, este último, que le confiere un significado contrario al del texto de Estacio, al que, no obstante, remite gracias al intertexto de Virgilio que comparten ${ }^{41}$.

Como ha señalado con frecuencia la crítica, la inversión que el final del libro XI de la Tebaida hace de los versos que dedica Virgilio a Euríalo y Niso es evidente ${ }^{42}$. Del mismo modo, el uso como intertexto por parte de Silio Itálico (XVI 529-548) de este pasaje de Estacio (Ripoll 2015, p. 431) ${ }^{43}$ permite extender a los gemelos hispanos, movidos por el regni furor (Sil. XVI 540), la condena dirigida a Eteocles y Polinices por Estacio y entender su final como antífrasis del de Euríalo y $\mathrm{Niso}^{44}$. Así, la alusión, aceptada de modo general, del final de los trillizos al apóstrofe virgiliano, refuerza, por contraste, el significado positivo que pretende dar Silio a este enfrentamiento. Y además encuentra una motivación para la reutilización del epifonema de Virgilio en una estructura narrativa que en nada se parece a la del original virgiliano. Que Silio y Estacio recurran a un mismo intertexto en pasajes de contenido semejante y de

${ }^{41}$ En este caso, según Ripoll 2015, p. 431, Silio imita a Estacio; cf. Lovatt 2010, p. 161.

42 Ganiban 2007, p. 202, Lovatt 2005, p. 256, McNelis 2007, p. 148. Bessone 2011, p. 82, entiende como paradójico que se pida el olvido de algo que es «il mito di fondazione dell'odio fraterno e della discordia civile che nascono della passione del potere e dalla divisione del regnum: un mito destinato a replicarsi in ogni tempo e in ogni luogo, e più che mai nella storia romana antica e recente».

${ }^{43}$ McGuire 1997, pp. 100-101, señala otros elementos claramente estacianos en Silio: la repetición de la terminología real (regibus... regnis), la colocación enfática de furorem y dextris, y el hipérbaton que destaca la expresión impia proelia.

${ }^{44}$ Aunque la relación señalada por Dominik 2003, p. 489, entre esta inversión y el discurso a las almas de los saguntinos que les dirige Silio Itálico (II 696-698), parece oportuna, las implicaciones de su análisis no resultan tan convincentes. En cambio, parece invertir el sentido de la despedida de Estacio a Eteocles y Polinices, cf. Venini (1970 ad Theb. 11.574 ss.) en Bessone 2011, p. 85 n. 3. 
sentido contrario, pero absolutamente distantes del original, permite deducir que hay una estrecha vinculación entre ellos. Si, de acuerdo con Bessone 2011, pp. 82-83, consideramos que los versos del apóstrofe virgiliano son los versos que tal vez mejor resuman el estatuto del género épico, parece claro que podemos entender que en el relato de los trillizos estamos ante una expresión programática de la obra épica de Silio contrapuesta a la de Estacio: una épica en la que la gloria militar y la celebración y conmemoración de las hazañas son posibles (Bessone, 2013: 92) frente a esa otra épica del nefas, que niega la posibilidad de celebrar la gloria bélica ${ }^{45}$. Conviene recordar que la lucha de los trillizos se plantea también como un acto heroico, una prueba de la uirtus guerrera, aunque en el apóstrofe final sea la pietas, siguiendo el modelo de Virgilio, la virtud destacada ${ }^{46}$. La repetición de uno de los términos claves del proemio de Silio (decus memorare laborum I 3) en el epílogo del combate (aeternum decus memori celebrabitur aeuo IV 398) refuerza dicha idea.

El paralelismo de los textos de Silio con otros similares de Estacio, especialmente con el apóstrofe a los Tespíadas (X 445), permite extender las relaciones intertextuales entre ambos poetas. En la obra de Estacio se reproduce la relación intratextual de las Púnicas entre textos cuya idea nuclear es la oposición entre pietas e impietas que se encarna en las imágenes de la guerra civil. Estacio pone en escena, por contraste, parejas de hermanos ejemplares que sirven de modelo opositivo a la pareja central enfrentada. Es una forma de ilustrar que existen otras posibilidades, a la vez que recuerda que la amenaza de la elección de la peor opción siempre está presente. Un ejemplo claro lo constituyen los gemelos Toante y Euneo. Su actitud en el trascurso de los juegos fúnebres del libro VI de la Tebaida es contraria a la de los gemelos hispanos, pues compiten por no superarse ${ }^{47}$; y remite expresamente a la pietas de los trillizos: Cedunt uincuntque, nec unquam / ambitiosa pios collidit gloria fratres (Theb. VI 434-35).

Más cercano a los casos planteados es, sin embargo, el final de los gemelos Tespíadas ${ }^{48}$ :

45 Sobre el valor del episodio en Virgilio, cf. Hardie 1994, p. 153 ss.

${ }^{46}$ Asimismo, induce la comparación entre ambos pasajes la presencia de la figura de la Pietas personificada en un momento anterior al combate decisivo entre los dos hermanos tebanos (Theb. XI 482-96), cf. Ripoll 1998 y Walter 2013.

47 Esta armonía se diseña como antítesis de la discordia entre Eteocles y Polinices por un lado, y la de los gladiadores silianos por el otro, como afirma Ariemma 2008.

${ }^{48}$ Cf. Hardie 1993a, p. 63 y n. 13, y Bessone 2011, p. 85. 
Vos quoque, Tespiadae, cur infitiatus honora arcuerim fama? fratris moribunda leuabat membra solo Periphas (nil indole clarius illa nec pietate fuit), laeua marcentia colla sustentans dextraque latus; singultibus artum exhaurit thoraca dolor, nec uincla coercent undantem fletu galeam, cum multa gementi pone grauis curuas perfringit lancea costas exit et in fratrem cognataque pectora telo conserit. ille oculos etiamnum in luce natantes sistit et aspecta germani morte resoluit. at cui uita recens et adhuc in uulnere uires 'hos tibi complexus, haec dent' ait 'oscula nati.' procubuere pares fatis, miserabile uotum mortis, et alterna clauserunt lumina dextra. (II 629-643)

Estos hermanos ilustran una forma de acceso a la fama basada en una virtud excepcional, la piedad fraterna ${ }^{49}$, uno de los motivos de glorificación en una obra que no puede celebrar la gloria épica tradicional.

No obstante, encontramos un pasaje de Estacio que recupera de forma explícita el apóstrofe virgiliano en un contexto más próximo al de los jóvenes Euríalo y Niso. Se trata del episodio de la muerte de los compañeros Hopleo y Dimas (X 347-448), cuyo inicio coloca la pietas como elemento clave: Inuida fata piis et fors ingentibus ausis / rara comes (vv. 384-385) ${ }^{50}$. Este pasaje se vincula con el texto de Silio especialmente a través del intertexto virgiliano al que recurren ambos ${ }^{51}$ :

49 Markus 2003, Walter 2013, p. 324.

${ }^{50}$ La importancia y significado de la pietas en este texto la estudian entre otros Markus 1997, Ganiban 2007, pp.131-136. Ripoll 1998, p. 302, por su parte, analiza con detalle los diferentes casos de pietas con final trágico y los de pietas recompensada para concluir que los pasajes que ilustran esta última (I 557-672 y XII 105 ss.), por su misma posición, principio y final de la obra, encuadran el resto y con ello relativizan el aparente pesimismo de la obra en su conjunto. Por su parte, Criado 2000, p. 114, toma este episodio como una muestra de la falta de énfasis en la consecución de la gloria, característica de la obra de Estacio frente a la de Homero y Virgilio.

${ }^{51}$ Bessone 2011, p. 83, n. 5. Ganiban 2007, p. 3, y especialmente 133, señala la distancia con la Eneida por reclamar a Virgilio en un episodio que culmina con la falta de recompensa de la pietas (Ripoll, 1998, p. 302). Estacio (Theb. X 378-80) subraya la piedad de Dimas y Hopleo mediante la imagen arquetípica de la pietas virgiliana, y celebra su noble acción que 
uos quoque sacrati, quamuis mea carmina surgant

inferiore lyra, memores superabitis annos.

forsitan et comites non aspernabitur umbras

Euryalus Phrygiique admittet gloria Nisi. (Theb. X 445-448)

La relación no sorprende en cuanto que existen una serie de motivos comunes que permiten la introducción de elementos distintos, pero cercanos, en los esquemas tradicionales. Markus 2003, pp. 465-467, entiende que Estacio no puede ensalzar la gloria de héroes cuyo valor se manifiesta en una guerra fratricida, y subvierte así la ideología épica basada en la consecución de la gloria. En episodios como el de Hopleo y Dimas no se celebra la gloria militar sino el acto de pietas $^{52}$. Esta celebración posee la función de conectar con la tradición épica, por lo que parece destacar más la relación poética entre los personajes de Eneida y Tebaida que el elogio de la acción realizada. El carácter explícito de la relación intertextual demuestra la solución de compromiso a la que llega el poeta de la Tebaida. Esta explicación ayuda además a esclarecer las diferencias en la utilización del arquetipo virgiliano por parte de Silio y de Estacio; más aún si tenemos en cuenta que la elaboración del apóstrofe a Eteocles y Polinices es una inversión manifiesta del que Virgilio dedica a Euríalo y Niso. El clímax de la Tebaida se plantea así como una inversión de la Eneida en un lugar clave y, con ello, se produce la negación del estatuto épico allí expresado en forma tradicional ${ }^{53}$. Silio Itálico, sin embargo, recupera, no sin ambigüedades, el modelo tradicional para glorificar a

finaliza trágicamente. La relación de este texto con el de Silio a través del intertexto virgiliano resulta evidente, pero cabe destacar que, a su vez, Silio construye otro episodio de salida nocturna con un sentido completamente opuesto (VII 279 ss.), como señala Littlewood 2013, pp. 290-91, en respuesta al de Estacio. La interacción y el diálogo entre ambos autores son, por tanto, constantes y manifiestos.

52 Ripoll 1998, pp. 233-236, en su análisis de estos pasajes reduce a dos las formas de alcanzar gloria en el marco de la Tebaida: la muerte voluntaria estoica y un acto extraordinario de pietas.

${ }^{53}$ Se ha destacado con frecuencia la interferencia de la tragedia en la épica de Estacio (cf. Bessone 2011), sin embargo conviene no olvidar, como señala Criado 1999, p. 161, que el pathos no es exclusivo de la tragedia y que «el género épico consentía y fomentaba, como la preceptiva aristotélica documenta, esta promiscuidad». No vamos a entrar en la cuestión del valor metapoético de la alusión, para lo que remitimos al artículo de Río Torres-Murciano sobre las imitaciones del apóstrofe virgiliano en los poetas flavios (2009); sin embargo, sí nos interesa destacar la mayor proximidad a Estacio que al propio Virgilio en la formulación de la perduración de la propia poesía que señala el autor citado. Sobre la cuestión de la su- 
los trillizos (IV 396-400). La falta de una inversión del paradigma virgiliano en el caso de los gemelos hispanos, que impide un paralelismo completo entre los textos de Silio y Estacio analizados, no impide, sin embargo, esta interpretación; es más, su inclusión podría entorpecerla, otorgando una importancia excesiva a un suceso con suficientes características de guerra civil y ecos que cualquier lector podría perfectamente percibir.

En ambos autores observamos un vínculo estrecho entre textos de considerable valor a la hora de determinar, por un lado, la concepción del género y sus formas de inversión (épica del nefas / épica de la gloria) de cada uno de los poetas expresada mediante el uso directo y antifrástico de un texto clave de la Eneida; por otro, la profundidad del diálogo intertextual entre ellos y con los predecesores que representan las dos concepciones de la épica señaladas: Virgilio y Lucano.

En la Tebaida el uso positivo del intertexto virgiliano posee una presencia importante, pero se mantiene en un nivel secundario; muestra la existencia de posibilidades alternativas (Bessone 2011, p. 85), aunque el enfrentamiento final entre los hermanos al que conduce la obra impregna el conjunto con la mancha del scelus, del nefas ${ }^{54}$, permitiendo que los ejemplos positivos actúen tan sólo como elementos de contraste sin capacidad para debilitar la línea predominante ${ }^{55}$, como prueba la inversión del famoso epílogo en el momento culminante de la obra: en Silio, en cambio, el carácter celebrativo es el prioritario según indica Ripoll 1998, p. 254; de ahí el recurso al intertexto virgiliano para un episodio como el analizado, si bien con matizaciones importantes. La referencia, dentro del apóstrofe al comportamiento de los hermanos

cesión poética entre los épicos posteriores a Virgilio, remitimos a Hardie 1993b, pp. 98-119, y Barchiesi 2000.

${ }^{54} \mathrm{Si}$ bien la interpretación optimista de la Tebaida postula que en el libro XII se interrumpe la influencia del nefas, no creemos que este hecho obstaculice la interpretación que venimos defendiendo en cuanto que, bien por responder a una visión pesimista del poeta, o bien por deseo de expresarlo en toda su crudeza para condenarlo antes de conjurarlo, la presencia del nefas y su punto culminante en el libro XI son indiscutibles. Por ello, nos parece adecuada la valoración de Ahl 1986, p. 2904: «His epic of politics, power, and war does not pretend to glamorize its protagonists or to romanticize and glorify man's destruction of his follow men. It does not idealize and justify military prowess and success. It reminds us rather, that innocence, beauty and life itself must almost inevitably be destroyed».

${ }^{55}$ No pretendemos entrar en la discusión entre la visión optimista y pesimista sobre el final de la Tebaida, para lo que remitimos al resumen de la cuestión que realiza Bessone 2008, 2011, p. 128 ss., y a las sugerentes aportaciones de Criado 2015. 
venideros es una anticipación y una clara advertencia de las guerras civiles que se sucederán en Roma, en completa consonancia con los indicadores y referencias continuas a ella, que hemos señalado en el inicio de este artículo.

La reelaboración del combate de los trillizos responde a la dualidad que articulan las Púnicas, el carácter celebrativo de su contenido, el mayor de la épica latina (Ariemma, 2008), y el pesimismo respecto al futuro que se refleja en las referencias a las guerras civiles.

\section{Conclusión}

El ejercicio intertextual realizado por Silio se basa en la utilización de un doble método de evocación de la guerra civil con el fin de recordarla a sus contemporáneos (esto es, hacerla presente) y desmentir su inevitabilidad ofreciendo posibilidades distintas: por un lado, la conformación de los acontecimientos al modelo de lucha fratricida, y, por otro, la utilización de ejemplos que intentan demostrar la existencia de fuerzas capaces de cancelar u obstaculizar dicha fatalidad. Esta aproximación es imprescindible para trazar sobre esta base una forma alternativa del género, una forma que ofrezca la posibilidad de la superación de ese mal que parece ser un trágico destino inscrito de la historia de Roma. Esta dicotomía tiene sus consecuencias en la poética del autor, pues se traslada al modelo de épica que Silio escoge para su obra, y se inclina por la épica celebrativa pero la matiza de manera importante estableciendo así un fructífero diálogo con la tradición épica y con sus contemporáneos. Del mismo modo que parece surgir una alternativa positiva en la Tebaida podemos decir igualmente que las Púnicas entreteje en medio de la glorificación los aspectos oscuros de la historia de Roma.

El pasaje escogido (IV 355-400) ilustra a la perfección esta idea, expuesta en otros episodios de las Púnicas, como se ha podido observar, porque conjuga ingredientes diversos y contradictorios que necesitan una explicación y concluye con una alusión virgiliana que posee un carácter programático: Se trata una declaración indirecta de la concepción del género épico en su conjunto y de la obra épica concreta que elabora Silio Itálico, cuyo programa poético dominante había quedado establecido en el prefacio (gloria, I 1) y repetido en el epílogo del pasaje analizado (decus, IV 398). La utilización por parte de Estacio del mismo intertexto virgiliano tanto en su forma directa como inversa, enfatiza el carácter dialógico que posee dicha alusión y refuerza el valor programático que le hemos asignado. La ausencia de la inversión de dicho intertexto en el final 
del combate de los gemelos hispanos ratifica la distancia entre los planteamientos de ambos autores. El universo poético de Estacio se introduce, sin duda, en el de las Púnicas y condiciona y limita la exaltación del triunfo. El narrador de las Púnicas ensombrece el momento culminante de la gloria romana mediante las alusiones a las guerras civiles, y así ocurre en el episodio de los trillizos; sin embargo, por encima de ello, propone, sea desde la perspectiva del futuro (el tiempo de la narración) o del pasado (el tiempo del relato) como nostalgia, un modelo de épica alternativo al de Lucano y diferente al de Estacio.

\section{BIBLIOGRAFÍA}

Ahl, F. 1986: «Statius’ Thebaid: A Reconsideration», ANRW II 32.5, pp. 2803-2912. Ahl, F., Davis, M. A. y Pomeroy, A. 1986: «Silius Italicus», ANRW II 32.4, pp. 2492-2561.

Albrecht, M. von, 1964: Silius Italicus. Freiheit und Gebundenheit römischer Epik, Ámsterdam.

Aricò, G. 2010: «Pulchrae certent de laude Coronae. Alcune note sull'episodio dei ludi in Silio Italico XVI 303 ss.», en Castagna, L., Galimberti Biffino G. y Riboldi Ch. (eds.), Studi su Silio Italico, Milán, pp. 121-134.

Ariemma, E. M. 2000: Alla vigilia di Canne. Commentario al libro VIII dei Punica di Silio Italico, Nápoles.

Ariemma, E. M. 2008: «Odia fraterna, fraternae acies: I gemeli gladiatori in Silio Italico (Pun. 16.527-48)», Lexis 26, pp. 325-369.

Augoustakis, A. 2010 (ed.): Brill's Companion to Silius Italicus, Leiden - Boston.

Barchiesi, A. 2000: «Genealogie letterarie nell'epica imperiale. Fondamentalismo e ironia», en Schmidt E. A. (ed.), L'histoire littéraire immanente dans la poésie latine, Vandœuvres - Ginebra, pp. 315-362.

Bartolomé, J. 2009a: «El proemio de la Farsalia de Lucano y su recepción I», $C F C(L), 29$, pp. 37-56.

Bartolomé, J. 2009b: «El proemio de la Farsalia de Lucano y su recepción II» $C F C(L), 29$, pp. 65-83.

Bartolomé, J. 2010: «Del mito de fundación al mito de la destrucción en la épica de Lucano», en: Actas del XVII Simposio de la SELGYC, Barcelona, pp. 191-204.

Bessone, F. 2008: «Teseo, la clementia e la punizione dei tiranni: Esemplarità e pessimismo nel finale della Tebaide», Dictynna 5, 2008. $<$ http://dictynna.revues. org/200> (10/04/2017).

Bessone, F. 2011: La Tebaide di Stazio. Epica e potere, Pisa - Roma.

Bessone, F. 2013: «Critical Interactions. Constructing Heroic Models and Imperial Ideology in Flavian epic», en Manuwald, D. y Voigt, A. (eds.), pp. 87-106. 
Boyle, A. J. y Dominik W. J. (eds.) 2003: Flavian Rome. Culture, Image, Text, Leiden - Boston.

Chaudhuri, P., Dexter Joseph P. y Bonilla Lopez, Jorge A. 2015: «Strings, Triangles, and Go-betweens: Intertextual Approaches to Silius' Carthaginian Debates», Dictynna 2015. <http://dictynna.revues.org/1156> (11/01/2017).

Criado, C. 1999: «Tragicidad y epicidad de la Tisífone estaciana», CFC (L) 16, pp. 141-161.

Criado, C. 2000: La teología de la Tebaida estaciana. El anti-virgilianismo de un clasicista, Zúrich - NuevaYork.

Criado, C. 2015: «The Constitutional Status of Euripidean and Statian Theseus: Some Aspects of the Criticism of Absolute Power in the Thebaid», en Dominik, W. J., Newlands C. E. y Gervais, K. (eds.), pp. 291-306.

Dominik, W. J. 1990: «Monarchal Power and Imperial Politics in Statius’ Thebaid», en Boyle, A. J. ( ed.), Flavian Epicist to Claudian. The Imperial Muse Ramus Essays on Roman Literature of the Empire, Victoria (Australia), pp. 74-97.

Dominik, W. J. 1994: The Mythic Voice of Statius. Power and Politics in the Thebaid, Leiden - Nueva York - Colonia.

Dominik, W. J. 2003: «Hannibal at the Gates. Programatising Rome and Romanitas in Silius Italicus' Punica. 1 and 2», en Boyle A. J. y Dominik W. (eds.), pp. 469-497.

Dominik, W. J. 2017: «Civil War, Parricide, and the Scepter / Sword in Silius Italicus' Punica» en Ginsberg, L. D. y Krasne, D. (eds), Flavian Literature and Civil War, Berlín -Boston.

Dominik, W. J., Newlands, C. E. y Gervais, K., (eds.) 2015: Brill's Companion to Statius, Leiden - Boston.

Fröhlich, U. 2000: Regulus Archetyp römischer Fides. Das sechste Buch als Schlüssel zu den Punica des Silius Italicus, Tubinga.

Fucecchi, M. 1999: «La vigilia di Canne nei Punica e un contributo allo studio dei rapporti fra Silio Italico e Lucano», en Esposito P. y Nicastri, L. (eds.), Interpretare Lucano. Miscelanea di Studi, Nápoles, pp. 305-342.

Fucecchi, M. 2003: «I Punica e altre storie di Roma nell'epos di Silio Italico», en Casanova, A. y Desideri, P (eds.), Evento, racconto, scrittura nell'antichità classica, Florencia, pp. 267-292.

Fucecchi, M. 2006: Una guerra in Colchide: Valerio Flacco, Argonautiche 6, 1-426, Pisa.

Ganiban, R. T. 2007: Statius and Virgil. The Thebaid and the Reinterpretation of the Aeneid, Cambridge.

Hardie, Ph. 1993a: «Tales of Unity and Division in Imperial Latin Epic» en Molyneux J. H. (ed.), Literary Responses to Civil Discord, Nottingham, pp. 57-75.

Hardie, Ph. 1993b: The Epic Successors of Virgil, Cambridge. 
Hardie, Ph. 1994: Virgil, Aeneid Book IX, Cambridge.

Küppers, J. 1986: Tantarum causas irarum. Untersuchugen zur Enleitenden Bücherdyade der Punica des Silius Italicus, Berlín - Nueva York.

Landrey, L. 2014: «Skeletons in Armor. Silius Italicus' Punica and the Aeneid's Proem», AJPh 135, pp. 599-635.

Laudizi, G. 1989: Silio Italico. Il passato tra mito e restaurazione etica, Galatina.

Littlewood, R. J. 2011: A Commentary on Silius Italicus'Punica 7, Oxford.

Littlewood, R. J. 2013: «Invida fata piis? Exploring the significance of Silius' divergence from the night raids of Virgil and Statius», en Manuwald, G. y Voigt, A. (eds.), pp. 279-296.

Lovatt, H. 2005: Epic Games: Sport Politics and Poetics In Statius' Thebaid, Cambridge.

Lovatt, H. 2010: «Interplay: Silius and Statius in the Games of Sil. XVI», en Augoustakis, A. (ed.), pp. 155-176.

Marks, R. 2005: From Republic to Empire. Scipio Africanus in the Punica of Silius Italicus, Fráncfort del Meno.

Marks, R. 2010: «Silius and Lucan», en Augoustakis, A. (ed.), pp. 127-153.

Markus, D. D. 1997: «Transfiguring Heroism: Nisus and Euryalus in Statius'Thebaid», Vergilius 43, 56-62.

Markus, D. D. 2003: «The Politics of Epic Performance in Statius», en Boyle, A. J. y Dominik W. J. (eds.), pp. 431-467.

McGuire, D. T. 1997: Acts of Silence. Civil War, Tyranny, and Suicide in the Flavian Epics, Hildesheim.

McNelis, Ch. 2007: Statius' Thebaid and the Poetics of Civil War, Cambridge.

Manuwald, D. y Voigt, A. 2013: Flavian Epic Interactions, Berlín - Boston.

Mencacci, F. 1987: «Orazi e Curiazi: uno scontro fra trigemini 'gemelli'», MD 18, pp. 131-148.

Mencacci, F. 1994: «Felices leti: I guerrieri gemelli nella epica latina», AFLF 15, pp. 15-30.

Micozzi, L. 1999: «Aspetti dell'influenza di Lucano nella Tebaide», en Esposito, P. y Nicastri, L. (eds.), Interpretare Lucano. Miscelanea di Studi, Nápoles, pp. 343-387.

Niemann, K. H. 1975: Die Darstellung der römischen Niederlangen in den Punica des Silius Italicus, Bonn.

Río Torres-Murciano, A. 2006: «Farsalia en la Cólquide. Acerca de dos símiles en el libro VI de las Argonáuticas de Valerio Flaco» Emerita 74, pp. 201-216.

Río Torres-Murciano, A. 2009: «Las secuelas del Fortunati ambo (Verg., Aen. IX 446-449): epopeya e imperio», Emerita 77, pp. 295-315.

Ripoll, F. 1998: La morale hérö̈que dans les épopées latines d'époque flavienne: Tradition et innovation, Lovaina - París. 
Ripoll, F. 2015: «Statius and Silius Italicus», en. Dominik, W. J., Newlands, C. E. y Gervais, K. (eds.), pp. 424-442.

Spaltenstein, F. 1986: Commentaire des Punica de Silius Italicus (livres 1 à 8), Ginebra.

Spaltenstein, F. 1990: Commentaire des Punica de Silius Italicus, (livres 9 à 17), Ginebra.

Tipping, B. 2010a: Exemplary Epic. Silius Italicus' Punica, Oxford.

Tipping, B. 2010b: «Virtue and Narrative in Silius' Punica», en Augoustakis, A. (ed.), pp. 193-218.

Walter, A. 2013: «Beginning at the End. Silius Italicus and the Desolation of Thebes», en Manuwald, D. y Voigt, A. (eds.), pp. 311-326.

Fecha de recepción de la primera versión del artículo: 15/02/2017

Fecha de aceptación: 04/08/2017

Fecha de recepción de la versión definitiva: 12/12/2017 